\title{
A organização do conhecimento arquivístico a partir da Diplomática: elementos históricos e conceituais de um método em revisão
}

La organización del conocimiento archivístico desde la diplomática: elementos históricos y conceptuales de un metodo en revisión

The organization of archival knowledge from diplomatics: historical and conceptual elements for a method in review

\author{
Natália Bolfarini TogNOLI \\ Faculdade de Filosofia e Ciências, UNESP, Avenida Hygino Muzzi Filho, 737, Marília, São Paulo, Brasil, CEP: 17525-900 \\ nataliatognoli@marilia.unesp.br
}

\begin{abstract}
Resumen
La Archivística se ha beneficiado en las últimas décadas de sus conexiones interdisciplinares para abordar los desafíos provocados por las nuevas formas de producción documental. Este estudio presenta el apoyo metodológico que proporcionan los estudios diplomáticos, demostrando que el objeto de estudio de la Archivística determina el método adoptado para la organización y representación de los documentos, así como la adaptación que sufren los métodos para ajustarse a la complejidad de los sistemas de creación de documentos.
\end{abstract}

Palabras clave: Diplomática. Archivística. Metodología. Teoría. Producción documental.

\section{Introdução}

Nos últimos 30 anos, a Arquivística tem se beneficiado de sua interdisciplinaridade para enfrentar os desafios promovidos pelas novas formas de produção documental. Neste sentido, disciplinas como a Ciência da Informação $(\mathrm{Cl})$ e a Diplomática fornecem bases teóricas e metodológicas para auxiliar a disciplina dos arquivos no tocante à organização do conhecimento arquivístico em uma nova e, muitas vezes, aterrorizante, realidade.

De qualquer parte que se olhe é possível observar as relações que a Arquivística guarda tanto com a $\mathrm{Cl}$ - por meio do conceito de informação orgânica registrada - tanto com a Diplomática, por meio do conceito de documento de arquivo. Desta feita, conclui-se que o objeto de estudo em comum entre essas disciplinas - informação registrada, ou documento de arquivo, são os responsáveis por tal interdisciplinaridade.

Pretende-se com esse trabalho demonstrar como o objeto de estudo da Arquivística - documento de arquivo/informação orgânica registrada - determina o método adotado para sua

\begin{abstract}
Recently Archival Science has used its interdisciplinarity connections to face the challenges offered by new forms of records creation. This paper presents the methodological support given by diplomatics studies, demonstrating how the object of Archival Science determines the method chosen for its organization and representation, and describes the adaptation of methods to the complexity of the document creation systems.
\end{abstract}

Keywords: Diplomatics. Archival science. Document production. Methodology. Theory.

organização e representação, no contexto dos estudos diplomáticos. Neste sentido, serão apresentados os métodos diplomáticos desenvolvidos durante os séculos XVII (Mabillon), XIX (Sickel), XX (Duranti) a fim de ilustrar: (1) o aporte metodológico dado à Arquivística pela Diplomática no tocante à organização e representação de sua informação; e (2) a "adaptação" sofrida pelos métodos durante os séculos, ocasionada pela complexidade dos sistemas burocráticos de criação de documentos.

Destaca-se, ainda o fato de o presente trabalho buscar contribuir para as questões teóricas que circundam as áreas em questão, que desde a década de 1960 são colocadas em contato, por Bautier (1962), graças ao estabelecimento das pièces des archives enquanto objeto de estudo da Diplomática.

Ressalta-se, por fim, que o presente artigo apresenta os resultados da tese de doutorado da autora, intitulada $A$ construção teórica da Diplomática: em busca da sistematização de seus marcos teóricos como subsídio aos estudos arquivísticos, defendida em 2013, que reali- 
zou um resgate teórico sistematizado da Diplomática a partir do estudo e análise das obras mais importantes para a constituição da área durante quase quatro séculos (XVII-XXI) de existência, identificando nelas aspectos convergentes e traços distintivos em relação ao método diplomático e ao objeto de estudo da área.

\section{Diplomática: origem e desenvolvimento}

A história da Diplomática está fundamentalmente ligada à das falsificações. Graças a elas, grandes obras foram escritas, buscando enunciar métodos e elementos para a verificação da autenticidade/falsidade de documentos. Essas obras constituem-se, na maioria, de tratados e manuais redigidos durante o Antigo Regime (ancièn regime) e a época moderna e, embora possuíssem objetivos diferentes, foram, ao longo dos anos, se complementando para formar as bases teóricas da disciplina. Neste item estuda-se a origem e o desenvolvimento das três abordagens da disciplina, conhecidas como Clássica (período que compreende a publicação dos tratados no antigo regime), Moderna (abordando os manuais modernos publicados no período de grande efervescência das ideias positivistas dos séculos XVIII e XIX) e Contemporânea (que compreende o período de final da década de 1960 até os dias de hoje).

É, seguramente, no século XVII, que surgem as primeiras formulações críticas e teóricas sobre 0 exame dos documentos, notadamente na Alemanha e na França. Os constantes episódios de discussão sobre a autenticidade/falsidade de diplomas que comprovavam direitos de propriedade enriqueceram o período com obras sobre a crítica dos documentos.

Dentre essas obras, destaca-se, aqui, De re diplomática (1681), de Jean Mabillon, considerada o primeiro grande tratado de Diplomática. Confrontando e analisando diplomas inseridos em uma série cronológica ou em um conjunto específico de documentos de uma determinada época ou lugar, Mabillon cria um "método" histórico, analítico-comparativo que sustenta o estudo crítico dos documentos até os dias de hoje.

Essas primeiras formulações apresentadas por Mabillon não podiam, no entanto, ser chamadas de "método". Na realidade, não houve nenhuma intenção por parte do autor em criar um método ou definir um objeto de estudo para a Diplomática. A necessidade prático-jurídica de estabelecer regras para a verificação da autenticidade/ falsidade de diplomas não permitiu, à época, um aprofundamento científico da Diplomática, faltando, em sua obra definições e conceitos que pudessem fortalecer a disciplina enquanto tal.
Dessa forma, o objeto de estudo da Diplomática neste primeiro momento eram apenas os diplomas (daí a origem do nome da disciplina), entendidos como os documentos mais solenes. Essa não definição do objeto de estudo da disciplina, levou alguns autores a creditar à MabilIon o nascimento das primeiras ideias concernentes à organização de documentos de arquivo, uma vez que os diplomas estavam, quase sempre, localizados em arquivos públicos ou privados e de ordens religiosas. Essa confusão perdura até hoje nas obras de autores como Duranti (1995a) e Heredia Herrera (1991).

Esse cenário muda no século XIX, com as publicações de Theodor Von Sickel, Beiträge zur Diplomatik, de 1861-1882 (publicada em 8 volumes), e Acta regum et imperatorum Karolinorum digesta et ennarata, de 1867 (com 2 volumes). O autor é o primeiro a dividir o documento em texto e protocolo, partição e nomenclaturas até então inexistentes na análise diplomática e que, após seus estudos, são considerados as partes principais de qualquer documento diplomático. Há também uma intenção em construir definições para a disciplina e seu objeto, refletindo o momento de ebulição científica que tomava aquela época. Neste contexto, emergem o conceito de documento diplomático (Urkunden) e a construção de uma crítica efetivamente válida, livre de interpretações, que pode ser considerada o primeiro método diplomático. Segundo o autor (Sickel, 1867, p. 02), o objeto da disciplina pode ser entendido como

[...] testemunho escrito, redigido segundo uma forma determinada - variável com relação ao lugar, à época, à pessoa, ao negócio, sobre fatos de natureza jurídica.

Durante todo o século XIX, várias obras sobre a Diplomática continuaram a serem escritas, e sua função prático-jurídica do século XVII deu lugar à função de ciência auxiliar da História. Refletindo o movimento historiográfico da época, que passa a entender o documento, principalmente aquele de arquivo, como testemunho mais fiel para a compreensão do passado, a Diplomática passa a ser estudada por historiadores com o objetivo de auxiliá-los nesta tarefa.

Ao período de ideias em efervescência, vivenciado pela Diplomática no século $\mathrm{XIX}$, notadamente com os estudos de Sickel e dos demais diplomatistas austríacos e alemães, seguiu-se um período de total estagnação, que encontrou, na segunda metade do século $X X$, ora defensores que proclamavam a urgência de uma revisão disciplinar em direção à ampliação do campo de estudo da Diplomática, ora defensores de uma manutenção da erudição da arte crítica, 
contra-atacando o caráter técnico que a disciplina ganhara nos últimos anos.

É somente em meados do século XX que a Diplomática liberta-se, em partes, da característica de auxiliar da História, e seus estudos finalmente tomam rumo a uma renovação disciplinar, quando, em 1962, o arquivista francês Robert-Henri Bautier lança as bases para a renovação da Diplomática, ao coloca-la em contato direto com a Arquivística por meio de seu objeto de estudo, entendido por ele como sendo o documento de arquivo (Tognoli, 2013, p. 94):

Bautier identifica, agora, como o próprio objeto da Diplomática todos os documentos mantidos nos arquivos, dos mais solenes (diploma) aos mais comuns (chartae) [...] Essa simbiose entre documento de arquivo e documento diplomático permite, segundo o autor, a compreensão do documento em função do fundo ao qual pertence ou pertenceu. Ao invés de estudar o documento diplomático isoladamente, deve-se compreendê-lo enquanto documento arquivístico, o que garante ao diplomatista uma melhor compreensão do contexto no qual o documento foi gerado, uma vez que as fontes são claramente maiores.

A abertura do objeto de estudo da Diplomática a todos os documentos de arquivo permitiu sua aproximação à Arquivística, dando origem, no final do século XX, a uma nova abordagem, conhecida como Diplomática Contemporânea, ou Diplomática Arquivística.

Esta terceira abordagem, cujos estudos são iniciados na Itália por Carucci (1987) e continuados e aperfeiçoados por Duranti no Canadá (1989 até hoje), defende a aplicação do método diplomático a qualquer documento de arquivo, independente de sua natureza ou suporte. No entanto, para que o método possa dar conta de uma realidade documental tão diferente, foram necessárias as incorporações de novos elementos, criando um método à parte, com base naqueles propostos por Mabillon e Ficker, mas que pudesse ser aplicado aos documentos contemporâneos, principalmente àqueles gerados eletronicamente.

Esse método sustenta, hoje, os estudos da Tipologia Documental e pode ser utilizado para a compreensão do contexto de criação dos documentos quando não é possível o conhecimento de outras fontes auxiliares para tanto. Ou seja, quando o arquivista não tem acesso ao organograma ou regimento interno da instituição, seu estudo pode partir diretamente do documento com o auxílio da análise diplomática. Dessa forma, a análise parte do documento e de suas partes para o fundo.
A seguir as diferentes abordagens do método diplomáticos são ilustradas para mais bem delinear as diferenças e semelhanças entre as Diplomática Clássica, Moderna e Contemporânea:

\begin{tabular}{|c|c|c|}
\hline Mét. & $\begin{array}{l}\text { Elementos } \\
\text { externos }\end{array}$ & Elementos Internos \\
\hline$\frac{c}{\frac{0}{\overline{0}}}$ & $\begin{array}{l}\text { Material, Tipos de } \\
\text { escritura, } \\
\text { Instrumentos }\end{array}$ & $\begin{array}{l}\text { Invocação } \\
\text { Subscrições, Selos } \\
\text { Estilo, Inscrição } \\
\text { Titulação, Precação, } \\
\text { Assunto, } \\
\text { Datas, Saudação }\end{array}$ \\
\hline $\begin{array}{l}\bar{\Phi} \\
\bar{v} \\
\bar{\omega}\end{array}$ & $\begin{array}{l}\text { Material, Tipos de } \\
\text { escritura, Selos, } \\
\text { Abreviatura, } \\
\text { Comentários }\end{array}$ & $\begin{array}{l}\text { Língua } \\
\text { Protocolo Inicial: Invocação, Nome e } \\
\text { título do autor } \\
\text { Texto: Preâmbulo, Nome, título do } \\
\text { destinatário, Exposição, Dispositivo, } \\
\text { Corroboração, Anúncio dos sinais de } \\
\text { validação } \\
\text { Escatocolo: Assinatura, Datas, } \\
\text { Precação }\end{array}$ \\
\hline 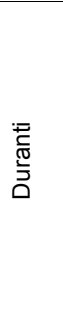 & $\begin{array}{l}\text { Meio, Escrita, } \\
\text { Linguagem, } \\
\text { Sinais especiais } \\
\text { Selos }\end{array}$ & $\begin{array}{l}\text { Protocolo Inicial: Timbre, Título do } \\
\text { documento, Datas, Invocação, } \\
\text { Subscrição, Inscrição, Saudação, } \\
\text { Assunto, Formula perpetuitatis, } \\
\text { Precação } \\
\text { Texto: Preâmbulo, Notificação, } \\
\text { Exposição, Dispositivo, Cláusulas finais } \\
\text { Escatocolo: Corroboração, Datas, } \\
\text { Precação, Saudação,Cláusula } \\
\text { complementar, Atestação, Qualificação } \\
\text { da assinatura, Notas secretariais }\end{array}$ \\
\hline
\end{tabular}

Quadro 1. As diferentes abordagens do método diplomático

O método diplomático é considerado um método analítico e comparativo porque primeiramente reparte os documentos em suas partes, analisando-as separadamente para, depois, compará-las com aquelas de outros documentos. Neste sentido, a Diplomática é compreendida como a disciplina que estuda a forma do documento, composta, necessariamente pelos elementos externos e internos.

As primeiras formulações metodológicas propostas por Mabillon consistiam em analisar as partes internas e externas do documento (seus elementos) inserido em uma série cronológica ou em um conjunto específico de documentos de uma determinada época ou lugar. Seus elementos eram confrontados e analisados com base em um contexto pré-estabelecido. Para tanto, Mabillon (1681, p. 41, tradução nossa) definiu-os como caracteres intrínsecos e extrínsecos, descrevendo os primeiros como o conteúdo do documento que abrange, por sua vez, o estilo, o texto, os selos, a data e as assinaturas. Os caracteres extrínsecos compreendiam o material (materia) sobre o qual eram escritos os documentos (pergaminho, papiro, tábuas de argila, chumbo, pedras) e o meio usado para inserir as escrituras ou símbolos nesse material (tinta). 
É a partir do século XIX, nos estudos de Sickel, que as coisas começam a mudar e o método diplomático é finalmente aperfeiçoado. Quando o ato jurídico e a gênese do documento começam a ter mais importância na análise diplomática, o método evolui, e as fórmulas préestabelecidas dão lugar à forma do documento. Esta, determinante para a criação de um documento juridicamente válido e relevante, passa a ter uma importância muito maior, assim como sua análise. Nesse contexto, novos elementos são incorporados ao método diplomático, e novas definições aparecem.

É nesse cenário que surge, em 1867, pela primeira vez, a divisão entre texto e protocolo no documento (Sickel, 1867, p. 107):

Eu chamo texto a parte central do documento e formulário ou protocolo o conjunto de fórmulas inicias e finais. Texto e protocolos são, portanto, os caracteres intrínsecos documentos.

Os protocolos funcionam, portanto, como a moldura do documento. Eles são responsáveis por abrir e fechar o teor documental, e às vezes manterão a mesma fórmula quando se trata de um mesmo autor ou de um mesmo ato jurídico. Seu principal ofício dentro da estrutura do documento diplomático é fornecer os elementos de validade legal. Já o teor documental, ou o texto propriamente dito, traz o conteúdo que pode variar segundo a natureza do ato jurídico.

O quadro 1 nos apresenta, portanto, os elementos externos e internos que compõem as diferentes abordagens do método diplomático. Dessa forma, em um primeiro momento podemos observar que os elementos externos não apresentam muita variação. No entanto, se formos destrincha-los a fundo, percebemos uma notável diferença entre os elementos propostos por Mabillon e Sickel e aqueles propostos por Duranti.

É claro que os elementos externos são enriquecidos ao longo do tempo, devido, em parte, à complexidade da documentação analisada. Os elementos propostos pelos autores da Diplomática Clássica e da Moderna são basicamente os mesmos, uma vez que os documentos analisados correspondem àqueles diplomas da Idade Média, variando somente em sua natureza pública ou privada. Quando há uma mudança no foco da arte crítica - dos diplomas aos documentos contemporâneos, notadamente àqueles eletrônicos - há a necessidade de incorporar novos elementos para analisá-los, emergindo, assim, o estudo do layout e do software, por exemplo. O mesmo pode ser observado com relação aos elementos internos. Após o método de Sickel, as divisões entre texto e protocolos se mantêm, com algumas alterações pertinentes ao contexto de produção documental da época analisada. Assim quanto mais complexo o sistema jurídico, mais complexo o documento e sua crítica.

Com base no exposto, pode-se dizer que o documento e sua natureza são os responsáveis por determinar o método diplomático - moderno ou contemporâneo - a ser utilizado na análise. Isso revela que o método contemporâneo não constituiu ruptura ou mudança de paradigma face ao método moderno, e sim uma alternativa a mais, que passa a coexistir com aquele, notadamente no contexto arquivístico.

Nessa abordagem diacrônica, há de se verificar ainda como se constitui o objeto de estudo da Diplomática ao longo das formulações metodológicas analisadas. Assim, tem-se:

\begin{tabular}{|c|c|}
\hline Autor & Objeto de estudo da Diplomática \\
\hline Mabillon & $\begin{array}{l}\text { Instrumentos autênticos e atos solenes: } \\
\text { Chartes eclésiatiques (documentos } \\
\text { eclesiásticos) } \\
\text { Diplomes royaux (diplomas reais) } \\
\text { Actes publics (documentos públicos) } \\
\text { Cédules privée (documentos privados) }\end{array}$ \\
\hline Sickel & $\begin{array}{l}\text { Urkunde: testemunho escrito, redigido } \\
\text { segundo uma forma determinada - } \\
\text { variável com relação ao lugar, à época, } \\
\text { à pessoa, ao negócio, sobre fatos de } \\
\text { natureza jurídica }\end{array}$ \\
\hline Duranti & $\begin{array}{l}\text { Unidade arquivística elementar } \\
\text { de natureza jurídica ou não }\end{array}$ \\
\hline
\end{tabular}

Quadro 2. Objeto de estudo da Diplomática segundo os autores

Quando Bautier identifica todos os documentos de arquivo como objeto da arte crítica, as fronteiras temporais são alargadas e, por essa razão, a Diplomática é revista. Assim, se para a análise de diplomas da Idade Média o método moderno é completo, para analisar a documentação contemporânea alguns elementos devem ser incorporados, como demonstrou Duranti.

\section{O aporte metodológico da Diplomática à organização do conhecimento arquivístico}

A Diplomática e a Arquivística passam a coexistirem a partir do século XIX. Antes disso os documentos de arquivo eram analisados pela Diplomática única e exclusivamente para a verificação de sua autenticidade. Com a fundação dos Institutos Europeus de História, há uma aproximação de ambas, uma vez que elas inse- 
riam-se, juntamente com a Paleografia, nos cursos de ciências auxiliares, com o intuito de fornecer bases metodológicas para tratamento da documentação histórica. Neste contexto podemos citar os exemplos da École des Chartes, na França (1821) e do Institut für Österreichische Geschichtsforschung, na Áustria (1854).

No entanto, apesar de coexistirem para um bem comum, ou seja, fornecer bases para os estudos históricos, ambas só começam a trabalhar juntas, buscando a organização do conhecimento arquivístico a partir do final da década de 1980, notadamente com os estudos de Carucci e Duranti.

Mas o que entendemos por conhecimento arquivístico? Mais ainda, por sua organização? Afim de esclarecer essas questões, valemo-nos do princípio basilar da Arquivística: o princípio da proveniência- respect des fonds.

O princípio da proveniência promulgado em 1841, em decorrência da necessidade de solucionar os problemas causados pela organização temática adotada pelos Arquivos Nacionais franceses, após a Revolução Francesa, é considerado o norteador dos processos de organização e representação na Arquivística e, talvez, o método mais seguro para preservar a integridade dos conjuntos documentais produzidos por uma pessoa ou instituição. Segundo Duchein (1983, p. 64) o princípio consiste em

[...] agrupar, sem misturar a outros, os arquivos (documentos de qualquer natureza) provenientes de uma administração, de um estabelecimento ou de uma pessoa física ou jurídica determinada: o que se chama de fundo de arquivo dessa administração, desse estabelecimento ou dessa pessoa.

Neste sentido, entende-se que os documentos agrupados em fundos refletem o conhecimento produzido por uma determinada pessoa ou entidade, definindo o que chamamos de conhecimento arquivístico. Há, portando, três atores principais neste contexto: (1) o criador (autor), que é a pessoa física ou jurídica responsável pela criação dos documentos; (2) o usuário, que irá utilizar a informação para fins administrativos ou jurídicos, ou ainda para fins históricos e, (3) os intermediários, que são os arquivistas ou outras pessoas responsáveis pela organização dos documentos.

O conhecimento arquivístico é, portanto, todo o conhecimento produzido por uma pessoa física ou jurídica e que está agrupado em um fundo documental. O princípio da proveniência é um dos guias para a organização desse conhecimento, no entanto, segundo Tognoli, Guimarães e Tennis (2013) não é mais suficiente para ga- rantir a criação, acesso e uso de documentos contemporâneos.

Neste sentido, observa-se que a Arquivística, passa por um momento de "crise" graças às novas tecnologias e formas de produção documental que desafiam os profissionais da informação. Em 1987, o arquivista Hugh Taylor previu uma mudança paradigmática na área, levando à necessidade de um reexame das bases da teoria arquivística. Segundo Taylor (1987, p. 14), não se trata apenas de documentos gerados em meios diferentes, de uma forma mais rápida.

Nós ficaremos anestesiados e paralisados [...] se continuarmos pensando que tudo o que temos são bits [...] o mesmo texto e imagem se movendo mais rápido e ocupando menos espaço, onde vemos fazer alguns ajustes tecnológicos para continuar no ramo.

Em busca de uma ressignificação da Arquivística e de suas metodologias para o tratamento de documentos emergentes em realidades completamente distintas, os arquivistas buscam na Diplomática (e em outras disciplinas) elementos para organizar o conhecimento arquivístico. Neste contexto, o método proposto por Sickel ganha uma nova abordagem, servindo como base para a Diplomática Arquivística ou Diplomática Contemporanêa.

Assim, para aplicar o método de análise dos documentos medievais aos contemporâneos, não é necessário reformular o conjunto de princípios e métodos da Diplomática estabelecidos nos manuais do século XIX, mas somente adaptá-los ao estudo dos conjuntos documentais contemporâneos, uma vez que a aplicação recai agora nos documentos arquivísticos, que mantêm uma relação direta do contexto com o conjunto.

A Diplomática oferece uma ferramenta para que os arquivistas compreendam tipos específicos de documentos. Essa ferramenta é o estudo da tipologia documental, que é uma aplicação do método proposto por Duranti. Esse método pode ser plicado claramente aos documentos contemporâneos e ao estudo de seus processos de criação. Nesse sentido, a Diplomática é muito utilizada no momento da identificação documental, seguindo a análise bottom-up, ou seja, do documento e suas partes para o contexto. Assim, segundo Duranti (1998, p. 6)

[...] a análise do arquivista vai gradualmente passando do contexto documental imediato do material sob análise para um contexto funcional mais amplo e, ainda, para um contexto sociocultural; ou seja, da realidade dos documentos para a imagem do criador dos documentos. 
Além disso, a Diplomática fornece elementos para a classificação e para a descrição de documentos de arquivo, notórios processos de organização.

No tocante à classificação, após a análise diplomática/tipológica do documento, é possível estabelecer os criadores e as funções documentais, elementos necessários à elaboração do plano de classificação. Dependendo do contexto é possível, identificar também, a estrutura da entidade produtora.

Em relação à descrição o aporte metodológico da Diplomática se faz ainda mais presente, notadamente no momento da análise documental. A Diplomática nos fornece elementos para além do conhecimento da forma do documento. Com o método, podemos também analisar seu conteúdo que, no documento de arquivo consiste em proveniência e função. Assim, elementos necessários à descrição de um fundo ou documento podem ser identificados a partir da análise diplomática, os quais destacamos o nome do produtor (proveniência - fundo, grupo, seção), as datas (tópica e cronológica), âmbito e conteúdo (do item documental), título do documento, dimensão e suporte (do item documental).

A Diplomática arquivística permite, portanto, que o arquivista chegue à compreensão do conjunto documental e de seu contexto a partir da crítica do documento. Desse modo, a análise do arquivista desloca-se desde o contexto documental imediato do material que examina até o amplo contexto funcional dos criadores de documentos e de suas relações.

\section{Considerações}

O presente estudo buscou demonstrar como método diplomático sustenta, hoje, as atividades de organização do conhecimento arquivístico, a partir do estudo de seu método e de suas diferentes abordagens.

Assim, destacamos que o objeto de estudo da Diplomática irá determinar o método a ser utilizado, comprovando que não houve uma evolução do método diplomático do século XVII ao século XXI, mas sim uma adaptação ou emergência de uma nova abordagem, levando os teóricos da área a inserir novos elementos ao método, de acordo com o objeto de estudo, no caso o documento de arquivo.

Dessa forma, embora tenha havido um movimento a favor da expansão dos limites tempo- rais da Diplomática, em meados do século $X X$, tal como preconizado por Bautier, o que pode ser observado é que não há, na realidade, uma expansão do objeto de estudo da Diplomática, e sim a emergência de uma nova abordagem, a Diplomática Arquivística, no final daquele século.

Enquanto a Diplomática Clássica e a Diplomática Moderna podem ser consideradas a mesma disciplina - Diplomática pura - admitindo-se uma evolução das formulações de Mabillon para o método de Sickel, a Diplomática contemporânea, por sua vez, pode ser considerada uma nova abordagem, uma vez que conta com a Arquivística para desenvolver seu método de análise de documentos, arquivísticos por natureza, na medida em que lhes é inerente o caráter orgânico.

\section{Referências}

Bautier, Robert-Henri (1961). Leçon d'ouverture du cours de diplomatique à L'Ecole des chartes. // Bibliothèque de l'Ecole des Chartes. 1961, 194-225.

Carucci, Paola (1987). II documento contemporaneo: diplomatica e criteri di edizione. Roma: La Nuova Italia Scientifica, 1987.

Duranti, Luciana (1989). Diplomatics: new uses for an old science (Part I). // Archivaria. 28 (Summer) 7-27.

Duranti, Luciana (1991).Diplomatics: new uses for an old science (Part V). // Archivaria, 32 (Summer) 6-24.

Duranti, Luciana (1995). Ciencia Archivistica. Córdoba.

Heredia Herrera, Antonia (1991). Archivística General: teoría

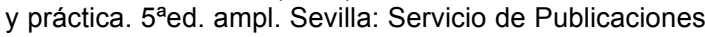
de la Dipustación de Sevilla.

Mabillon, Jean (1681). De re diplomatica libri sex. Paris.

Sickel, Theodor Von (1867). Acta regum er imperatorum Karolinorum digesta et enarrata. Wien: Duck und Verlag Von Carl Gerold's Sohn.

Taylor, Hugh A. (1987-88). Transformation in the Archives: Technological Adjustment or ParadigmShift? // Archivaria. 25 (Winter) 12-28.

Tognoli, Natália Bolfarini (2013). A construção teórica da Diplomática: em busca de uma sistematização de seus marcos teóricos como subsídio aos estudos arquivísticos. Tese (doutorado). Programa de Pós-Graduação em Ciência da Informação - Faculdade de Filosofia e Ciências, Unesp, Marília.

Tognoli, Natália Bolfarini; Guimarães, José Augusto Chaves; Tennis, Joseph (2013). Diplomatics as a methodological perspective for archival knowledge organization. // NASKO 2013: Transition Cultures, Transition KO: Evolving Exploration, Critical Reflection, and Practical Work. Milwaulkee. 216-227.

Enviado: 2014-04-01. Segunda versión: 2014-06-27. Aceptado: 2014-06-27. 